\title{
Changes in active and passive smoking in the European Community Respiratory
} Health Survey

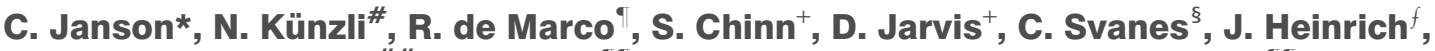

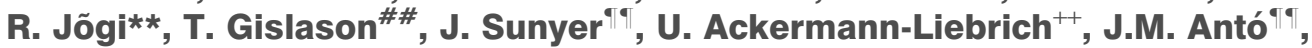 \\ I. Cerveri ${ }^{\S \S}$, M. Kerhof ${ }^{f f}$, B. Leynaert***, C. Luczynska ${ }^{+}$, F. Neukirch ${ }^{\star * *}$, \\ P. Vermeire ${ }^{\# \# \#, ~ M . ~ W j s t ~}{ }^{f}$ and P. Burney ${ }^{+}$
}

ABSTRACT: The aim of the present investigation was to study changes and determinants for changes in active and passive smoking.

The present study included 9,053 adults from 14 countries that participated in the European Community Respiratory Health Survey II. The mean follow-up period was 8.8 yrs. Change in the prevalence of active and passive smoking was expressed as absolute net change $(95 \%$ confidence interval) standardised to a 10 -yr period. Determinants of change were analysed and the results expressed as adjusted hazard risk ratio (HRR) or odds ratio (OR).

The prevalence of active smoking declined by $5.9 \%(5.1-6.8)$ and exposure to passive smoking in nonsmokers declined by $18.4 \%$ (16.8-20.0). Subjects with a lower educational level (HRR: 0.73 (0.54-0.98) and subjects living with a smoker (HRR: 0.45 (0.34-0.59)) or with workplace smoking (HRR: 0.69 (0.50-0.95)) were less likely to quit. Low socio-economic groups were more likely to become exposed (OR: $2.21(1.61-3.03)$ ) and less likely to cease being exposed to passive smoking (OR: 0.48 (0.37-0.61)).

In conclusion, the quitting rate was lower and the risk of exposure to passive smoking higher among subjects with lower socio-economic status. Exposure to other peoples smoking decreased quitting rates and increased the risk of starting to smoke.

KEYWORDS: Epidemiology, passive smoking, smoking, socio-economic status

$\mathbf{T}$ obacco is the world's biggest preventable killer and with 1.3 billion current smokers it is estimated that 450 million tobacco deaths will occur over the next 50 yrs unless current use changes dramatically [1]. It has also become evident that smoking is not only a problem for smokers, but also for those around them with mounting evidence of the harmful effect of passive smoking [2-4]. In the UK alone, passive smoking at home and in the workplaces has been estimated to cause deaths of $>10,000$ persons each year [4].

In the European Community Respiratory Health Survey (ECRHS) I, which included young adults (aged 20-44 yrs) from 16 countries, 37\% were active smokers [5] and 39\% of the never-smokers were exposed to passive smoking [6]. The ECRHS I was conducted in 1990-1994 and since then measures to reduce active and passive smoking have been introduced in many countries [7-9]. There are indications that these measures, to some extent, have been successful with declining prevalence of daily smoking in several countries [1012] and a decrease in exposure to passive smoking in English children during the 1990s [13]. Results from smoking cessation studies show a lower success rate in participants from lower socioeconomic groups [14, 15]. Having a smoking spouse $[15,16]$, a higher level of nicotine dependency, or higher tobacco consumption are other factors related to a lower quitting rate $[15,17]$.

The ECRHS II [18] was a follow-up study of the subjects that were investigated in the ECRHS I. This study provided a unique opportunity to study determinants of changes for active and passive smoking in population cohorts from a large number of different countries.

\section{METHODS}

The design of the ECRHS I and ECRHS II have been published in detail $[18,19]$. Each participant was sent a brief questionnaire (stage 1) and from
AFFILIATIONS

*Respiratory Medicine and Allergology, University of Uppsala, Uppsala, Sweden. \#Keck School of Medicine, University of Southern California, Los Angeles, CA, USA.

"University of Verona, Dept of Medicine and Public Health, Division of Epidemiology and Statistics, Verona Italy.

+Dept of Public Health Sciences, King's College London, London, UK.

${ }^{\text {s}}$ Dept Thoracic Medicine, Haukeland Hospital, Bergen, Norway.

fInstitute of Epidemiology, GSF-National Research Center for Environment and Health, Neuherberg, Germany.

${ }^{* \star}$ Tartu University Clinics, Lung Clinic Tartu, Estonia.

\#\#Dept Allergy, Respiratory Medicine and Sleep, University Hospital, Reykjavik, Iceland.

"Medical Research Institute (IMIM) Universitat Pompeu Fabra (UPF), Barcelona, Spain.

${ }^{+}$Institute of Social and Preventive Medicine, University of Basel, Basel, Switzerland.

${ }_{\S \S}$ Division of Respiratory Diseases, IRCCS "San Matteo" Hospital, University of Pavia, Pavia, Italy. ${ }^{f f}$ University of Groningen, Dept Epidemiology and Bioinformatics, University Medical Center Groningen, Groningen, The Netherlands. ${ }_{* * *}$ INSERM-The French Institute of Health and Medical Research, Paris, France.

\#\#\#University of Antwerp, Antwerp, Belgium.

CORRESPONDENCE

C. Janson, Dept of Medical Sciences, Respiratory Medicine and Allergology, Akademiska sjukhuset, SE 75185

Uppsala, Sweden. Fax: 46186110228 E-mail: christer.janson@medsci.uu.se

Received:

September 122005

Accepted after revision:

November 222005

SUPPORT STATEMENT

For further information regarding the

financial support received please see the Acknowledgements section.

European Respiratory Journal Print ISSN 0903-1936

Online ISSN 1399-3003 
those who responded, a random sample was selected to undergo a more detailed clinical examination (stage 2).

In the ECRHS II, subjects who had participated in stage 2 of the ECRHS I were invited to participate in the follow-up.
This analysis included data from 29 centres in the ECRHS II (table 1). The target population was 15,468 subjects with smoking data in stage 2 of the ECRHS I, of these 9,053 (58.6\%) supplied data on smoking in the ECRHS II. The follow-up time was $8.8 \pm 1.2$ yrs (mean $\pm \mathrm{SD}$ ).

TABLE 1 Prevalence of current and passive smoking in the European Community Respiratory Health Survey (ECRHS) I and II

Country and centre

Current smoking

Co

Iceland

Reykjavik

Norway

Bergen

Göteborg

Umeå

Uppsala

Estonia

Tartu

The Netherlands

Geleen

Belgium

Antwerp South

Antwerp City

Germany

Hamburg

Erfurt

Switzerland

Basel

France

Bordeaux

Grenoble

Montpellier

Paris

UK

Cardiff

Ipswich

Norwich

Italy

Pavia

Turin

Verona

Spain

Barcelona

Galdakao

Albacete

Oveido

Huevla

Australia

Melbourne

USA

Portland

All subjects
38.5

41.8

34.2

22.1

23.7

30.7

33.3

24.6

33.2

38.6

38.1

33.8

38.0

30.5

23.8

34.9

27.8

24.3

20.2

38.0

25.2

33.3

45.8

49.4

52.3

57.5

52.9

23.0

15.3

33.9
28.4

37.1

23.9

16.6

13.7

43.9

26.1

20.5

31.5

32.0

37.4

30.4

30.1

23.4

18.3

32.8

23.0

19.6

17.5

30.7

22.8

33.3

38.8

39.9

46.8

44.6

46.1

20.5

12.2

28.7
Passive smoking in nonsmokers

Follow-up

ECRHS II \%

n ECRHS I \% $\quad$ ECRHS II \%

Data are presented as mean $\pm \mathrm{SD}$, unless otherwise stated.

24.5

$8.9 \pm 0.3$

15.2

$9.5 \pm 0.2$

$9.1 \pm 0.4$

$8.5 \pm 0.4$

$8.6 \pm 0.4$

$5.2 \pm 0.4$

$10.3 \pm 0.3$

$9.8 \pm 0.4$

$9.1 \pm 0.4$

$9.3 \pm 0.6$

$9.2 \pm 0.3$

$10.3 \pm 0.4$

$9.2 \pm 0.5$

$9.1 \pm 0.4$

$9.2 \pm 0.7$

$8.2 \pm 0.9$

$10.6 \pm 0.2$

$8.5 \pm 0.5$

$9.0 \pm 0.5$

$8.5 \pm 0.7$

$8.4 \pm 0.4$

$8.7 \pm 0.6$

$8.9 \pm 0.7$

$8.6 \pm 0.4$

$8.7 \pm 0.8$

$8.4 \pm 0.7$

$8.4 \pm 0.7$

$7.0 \pm 0.5$

$7.7 \pm 0.4$

$8.8 \pm 1.2$ 


\section{Smoking}

Information on smoking history was collected by an administered questionnaire at each occasion. Those who answered "yes" to the lead question ("Have you ever smoked for as long as one year?") were asked "Do you smoke now, as of one month ago?" Subjects that were current smokers in the ECRHS I but not in the ECRHS II were defined as quitters. Subjects that were never-smokers in the ECRHS I but smokers in the ECRHS II were defined as starters. Questions on age when starting and quitting were used to determine when the change in smoking habits occurred during the study period. Information on the number of cigarettes, cigarillos, cigars and the amount of pipe tobacco consumed was collected in both surveys. Based on this information the quantity of smoking in the ECRHS I was assessed. The quantity was expressed as the average daily number of cigarettes, where cigarillos were assumed equivalent to three cigarettes and cigars to five, and pipe tobacco was converted to equivalence by weight [20].

\section{Passive smoking}

Passive smoking was assessed using different items from the questionnaire. The participants were asked whether they had regularly (most days or nights) been exposed to tobacco smoke in the last 12 months. Participants answering affirmatively to this question were classified as being passive smokers and then asked the number of other persons in the household who regularly smoked. Participants with at least one other active smoker in the household were classified as living with a smoker. Participants were also asked whether other people smoked regularly in the room where they worked and those who answered affirmatively were classified as being exposed to workplace smoking. Passive smoking was only assessed in subjects that were nonsmokers in both surveys, except when analysing the association between change in smoking status and living or working with smokers.

\section{Socio-economic status}

Socio-economic status was defined using information on the subject's occupation that was provided during the ECRHS I according to the UK social classification [21]. Using this classification the subjects were divided into: 1) professional and semi-professionals; 2) skilled nonmanual workers; 3) manual workers; and 4) undefined. A low educational level was defined as having completed full-time education before the age of 16 yrs [22].

\section{Age groups}

Based on the quartile distribution of the age in the ECRHS I, the subjects were divided into the following age groups: 20 $<28$; 28-<34; 34-<40; and 40-48 yrs.

\section{Body mass index}

Height and weight were measured in the majority of centres, self-reported in a few, prior to lung function measurement in the ECRHS I. The body mass index (BMI) was calculated as weight in kilograms divided by the square of the height in metres. BMI was analysed as a categorical variable divided into underweight $(<20 \mathrm{~kg})$, normal weight $(20-<25 \mathrm{~kg})$, overweight $(25-<30 \mathrm{~kg})$ and obese $(\geqslant 30 \mathrm{~kg})$.

\section{Ethics approval}

Local ethics committees at each centre approved the study protocols.

\section{Statistics}

Absolute change in smoking status per year of follow-up was estimated using population averaged generalised estimating equations for a binomial outcome with identity link. Participants were identified as the clustering factor and length of follow-up as an independent variable. Results were expressed as net change per $10 \mathrm{yrs}$ of follow-up. The Wald test was used to examine differences in change of prevalence by sex and age group.

Kaplan-Meyer and Cox regression was used to analyse determinants for change in smoking status and logistic regression for change in passive smoking status. The results were expressed as adjusted hazard risk ratio (HRR) and odds ratio, respectively, with a $95 \%$ confidence interval (CI). Age, sex, socio-economic status, centre and length of follow-up were used as independent variables in all models. Living with a smoker and workplace smoking were used as determinants for all analyses of change in active smoking status and the quantity of smoking in the ECRHS I in all analyses of determinants for quitting. Analyses of sex interactions were performed and, when a significant interaction was found, the logistic regression was performed for males and females separately. Estimates by centre or country were examined for heterogeneity and combined using random effects meta-analysis.

\section{RESULTS}

The present study included 9,053 subjects (4,313 males and 4,740 females), whose mean age at ECRHS I was $34.1 \pm 7.1$ (range 20-48) yrs. The participants in the ECRHS II were slightly older $(34.1 \pm 7.1$ versus $33.0 \pm 7.2)$ and less often smokers (33.9 versus $41.3 \%$ ) or manual workers (36.5 versus 41. $9 \% ; \mathrm{p}<0.0001)$ than subjects that only participated in the ECRHS I. Among the nonsmokers in the ECRHS I, the participants in the ECRHS II were exposed less often to passive smoking than the nonparticipants (40.6 versus $43.5 \%$; $\mathrm{p}=0.006)$.

\section{Change in prevalence of smoking}

The overall prevalence of smoking had decreased by $5.9 \%$ (5.16.8) when expressed as absolute change (95\% CI) per $10 \mathrm{yrs}$ of follow-up (table 1). There was a significant heterogeneity between the centres $(\mathrm{p}<0.0001)$ with a significantly decreased prevalence in 18 of the centres and a significant increase in one centre (Tartu, Estonia; fig. 1). Since the current smokers in the ECRHS I were under-represented in the ECRHS II, an adjusted estimate of change in smoking was made assuming that all the nonparticipants' smoking habits were unchanged. With this adjustment the overall decrease in the prevalence of current smoking was 3.4\% (2.8-3.9) per 10 yrs of follow-up.

Males had a significantly higher decline in the prevalence of current smoking than females and the decrease in the prevalence of smoking was significantly lower in the youngest age group than in the oldest age group (table 2). Differences in quit rates by sex and age were not significantly different between centres. 


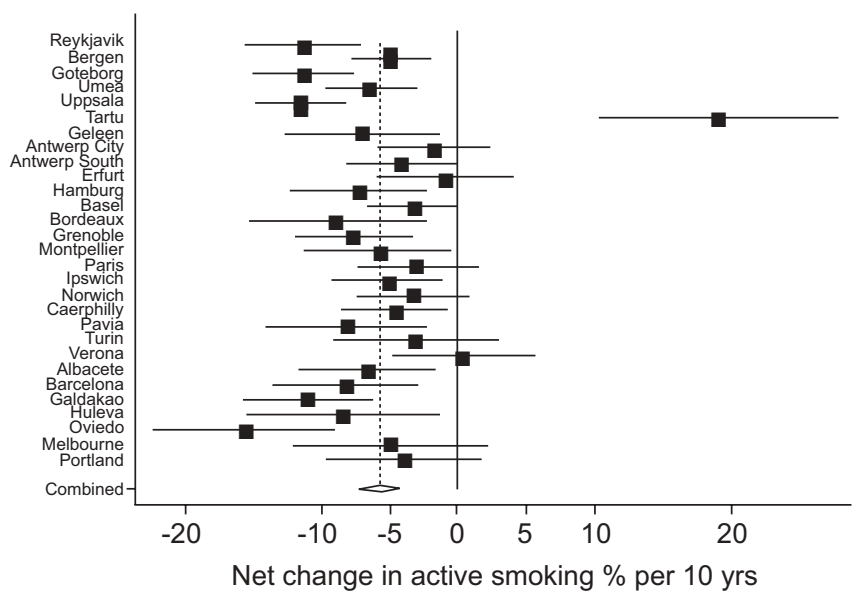

FIGURE 1. Net change in the prevalence of current smoking with $95 \%$ confidence interval $(\mathrm{Cl})$ in each centre. The area of each square is proportional to the reciprocal of the variance of the estimate for the centre. The diamond has the width of its $95 \% \mathrm{Cl}$. - . - - combined random effects estimate.

\begin{tabular}{|c|c|c|c|c|}
\hline TABLE & $\begin{array}{l}\text { Preva } \\
\text { Respi } \\
\text { smok }\end{array}$ & $\begin{array}{l}\text { nce of smoki } \\
\text { tory Health S } \\
g \text { during the }\end{array}$ & $\begin{array}{l}\text { in Europe } \\
\text { rvey I and } \\
\text { udy period }\end{array}$ & $\begin{array}{l}\text { an Community } \\
\text { hange in }\end{array}$ \\
\hline \multirow[t]{2}{*}{ Age yrs ${ }^{\#}$} & \multicolumn{2}{|c|}{ Females } & \multicolumn{2}{|c|}{ Males } \\
\hline & Prevalence & $\begin{array}{l}\text { Net change } \\
\cdot 10 \mathrm{yr}^{-1}\end{array}$ & Prevalence & $\begin{array}{c}\text { Net change } \\
\cdot 10 \mathrm{yr}^{-1}\end{array}$ \\
\hline $20-<28$ & 26.6 & $-2.0(-4.6-0.5)$ & 35.6 & $-4.7(-7.2--2.1)$ \\
\hline $28-<34$ & 31.9 & $-5.8(-8.2--3.3)$ & 39.0 & $-7.5(-10--4.9)$ \\
\hline $34-<40$ & 35.1 & $-4.1(-6.4--1.8)$ & 37.2 & $-9.0(-12-6.2)$ \\
\hline $40-48$ & 31.3 & $-6.0(-8.0--4.1)$ & 35.9 & $-8.9(-12,-6.3)$ \\
\hline $20-48$ & 31.2 & $-4.5(-5.7--3.3)$ & 36.9 & $-7.5(-8.9--6.2)$ \\
\hline
\end{tabular}

Data are presented as \%, unless otherwise stated. *: age difference of $p=0.002 ;{ }^{\prime}$ : sex difference of $p=0.001$.

\section{Determinants for change in active smoking status}

Among the 3,147 smokers in the ECRHS I, 822 (28.8\%) had stopped smoking during the follow-up, while 129 (3.2\%) of the 4,047 never-smokers in the ECRHS I were smokers in the ECRHS II. The chance of having stopped smoking was lower in the lowest socio-economic status group and in subjects with a lower educational level (fig. 2). The association between educational level remained significant after adjusting for exposure to other peoples smoking (table 3). Smokers that were living with other smokers or exposed to workplace smoking in the ECRHS II were less likely to have stopped smoking (fig. 3; table 3). The chance of quitting decreased with the quantity smoked in the first survey (table 3).

A significant sex interaction was found in the relationship between quitting and BMI $(\mathrm{p}=0.007)$. Overweight females (BMI $25-30 \mathrm{~kg} \cdot \mathrm{m}^{-2}$ ) were less likely to have stopped smoking than females with a normal BMI (HRR (95\% CI): 0.52 (0.35$0.78)$ ), whereas no association was found between quitting and
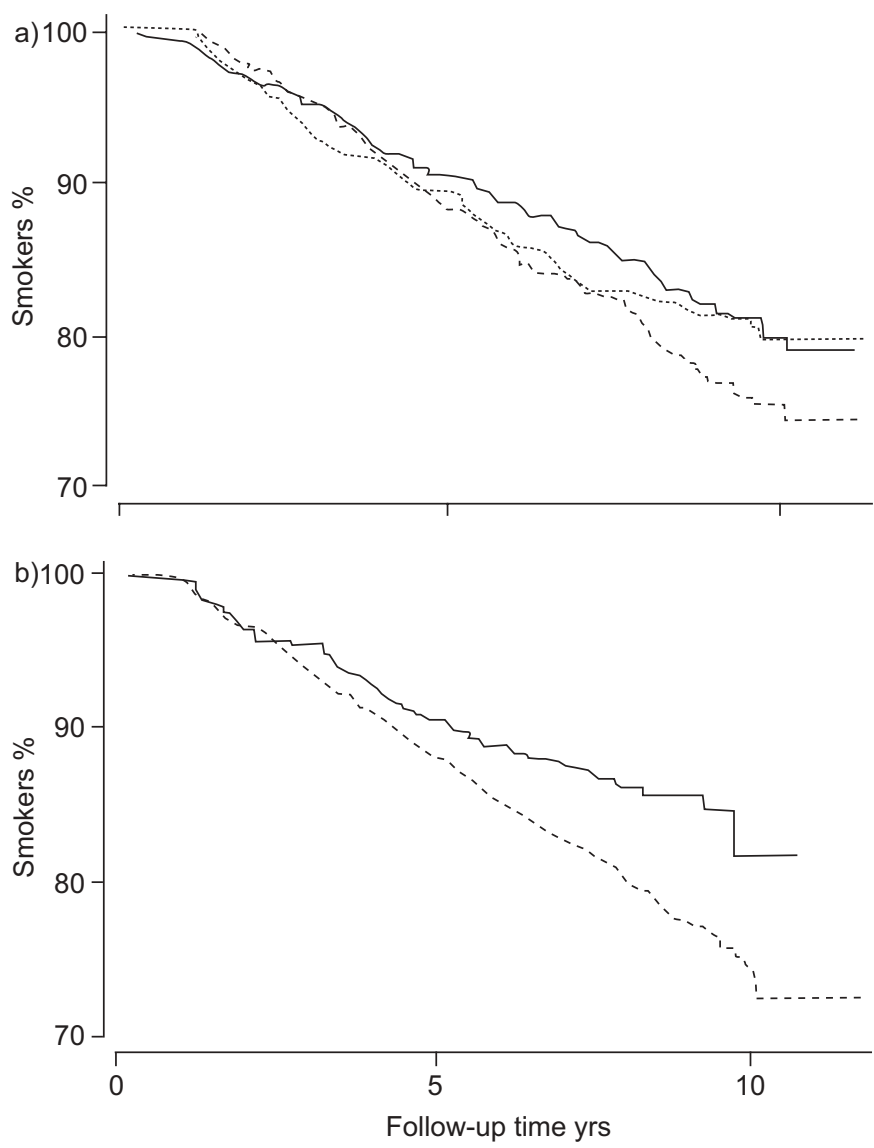

FIGURE 2. Proportion of smokers that continued smoking during the study period in relation to a) socio-economic status and b) educational level. —- low; --high; - - - -: intermediate. In socio-economic status $p=0.01$ and in educational level $p=0.002$

being overweight in males (1.05 (0.80-1.36)). Females were significantly less likely than males to stop smoking if they were living with a smoker in both surveys (HRR (95\% CI): 0.32 (0.21$0.50)$ versus 0.61 (0.43-0.87), $\mathrm{p}=0.03)$. No between-country heterogeneity was found in the association between quitting and sex, BMI, household smoking or smoking quantity.

The risk of having started smoking in previous never-smokers decreased with increasing age (table 3). Subjects that were living with a smoker in both surveys had a higher risk of starting to smoke (table 3).

\section{Change in the prevalence of passive smoking}

The overall exposure to passive smoking in subjects that were nonsmokers in the ECRHS I and II had declined by $18.4 \%$ (16.8-20.0) per 10-yr follow-up (table 1). There was a significant decrease in all but three centres, but there was still heterogeneity between the centres ( $p<0.0001$; fig. 4).

In the ECRHS I, the prevalence of passive smoking in nonsmokers at home was $17.9 \%$, while $20.6 \%$ were exposed to passive smoking at work. During the follow-up the prevalence of passive smoking at home had declined by $8.7 \%$ (7.5-9.8) per 10 yrs while the prevalence of passive smoking at work decreased by $10.9 \%$ (9.5-12.3) per 10 yrs. 


\begin{tabular}{|c|c|c|}
\hline \multirow[t]{2}{*}{ TABLE 3} & \multirow[b]{2}{*}{ Stopped smoking } & \multirow[b]{2}{*}{ Started smoking } \\
\hline & & \\
\hline Females & $0.85(0.72-1.01)$ & $0.62(0.32-1.21)$ \\
\hline \multicolumn{3}{|l|}{ Age in ECRHS I yrs } \\
\hline $40-48$ & 1 & 1 \\
\hline $34-<40$ & $0.99(0.79-1.25)$ & $5.08(0.56-46.1)$ \\
\hline $28-<34$ & $0.96(0.76-1.21)$ & $7.54(0.91-62.2)$ \\
\hline $20-<28$ & $0.77(0.60-0.99)$ & $22.2(2.93-168)$ \\
\hline Not living with a smoker & 1 & 1 \\
\hline $\begin{array}{l}\text { Living with a smoker in } \\
\text { ECRHS II }\end{array}$ & $0.43(0.28-0.65)$ & $3.06(0.95-9.90)$ \\
\hline $\begin{array}{l}\text { Living with a smoker in } \\
\text { ECRHS I }\end{array}$ & $1.09(0.90-1.33)$ & $1.45(0.52-4.06)$ \\
\hline $\begin{array}{l}\text { Living with a smoker in } \\
\text { both surveys }\end{array}$ & $0.45(0.34-0.59)$ & $4.78(2.03-11.2)$ \\
\hline No smoking at workplace & 1 & 1 \\
\hline $\begin{array}{l}\text { Workplace smoking in } \\
\text { ECRHS II }\end{array}$ & $0.68(0.48-0.97)$ & $1.32(0.39-4.42)$ \\
\hline $\begin{array}{l}\text { Workplace smoking in } \\
\text { ECRHS I }\end{array}$ & $1.06(0.86-1.30)$ & $1.33(0.55-3.22)$ \\
\hline $\begin{array}{l}\text { Workplace smoking in } \\
\text { both surveys }\end{array}$ & $0.69(0.50-0.95)$ & $1.59(0.55-4.65)$ \\
\hline Professionals & 1 & 1 \\
\hline Nonmanual & $0.90(0.71-1.16)$ & \\
\hline Manual & $0.88(0.71-1.09)$ & $1.13(0.40-3.22)$ \\
\hline Low educational level ${ }^{\#}$ & $0.73(0.54-0.98)$ & $1.02(0.38-2.78)$ \\
\hline \multicolumn{3}{|l|}{ Smoking in ECRHS I } \\
\hline$\leqslant 5$ cigarettes $\cdot$ week $^{-1}$ & 1 & \\
\hline$>5-\leqslant 10$ cigarettes $\cdot$ week $^{-1}$ & $0.81(0.64-1.03)$ & \\
\hline $\begin{array}{l}>10-\leqslant 20 \text { cigarettes. } \\
\text { week }^{-1}\end{array}$ & $0.66(0.53-0.81)$ & \\
\hline$>20$ cigarettes $\cdot$ week $^{-1}$ & $0.58(0.44-0.78)$ & \\
\hline
\end{tabular}

Data are presented as adjusted hazard ratio (95\% confidence interval). The hazard risk ratios were adjusted for centre and the variables in the table. ECRHS: European Community Respiratory Health Survey. \#: entered separately in the table, replacing occupational status.

\section{Determinants for change in exposure status to passive smoking}

Among the 2,213 nonsmokers who reported being exposed to passive smoking in the first survey, $55.8 \%$ reported being no longer exposed in the ECRHS II. However, $11.4 \%$ of the 3,226 nonsmokers that were not exposed to passive smoking in the ECRHS I reported being exposed to passive smoking in the ECRHS II.

Subjects in the youngest age group were more likely to have both become and ceased being exposed to passive smoking during the study period, while manual workers and subjects that stopped full-time education before the age of 16 yrs were less likely to have ceased being exposed and more likely to have become exposed during the follow-up (table 4). No between-country heterogeneity was found in relation to change in exposure status and age or socio-economic status. Analyses of change in passive smoking at home or at work showed a similar pattern to the analyses above.
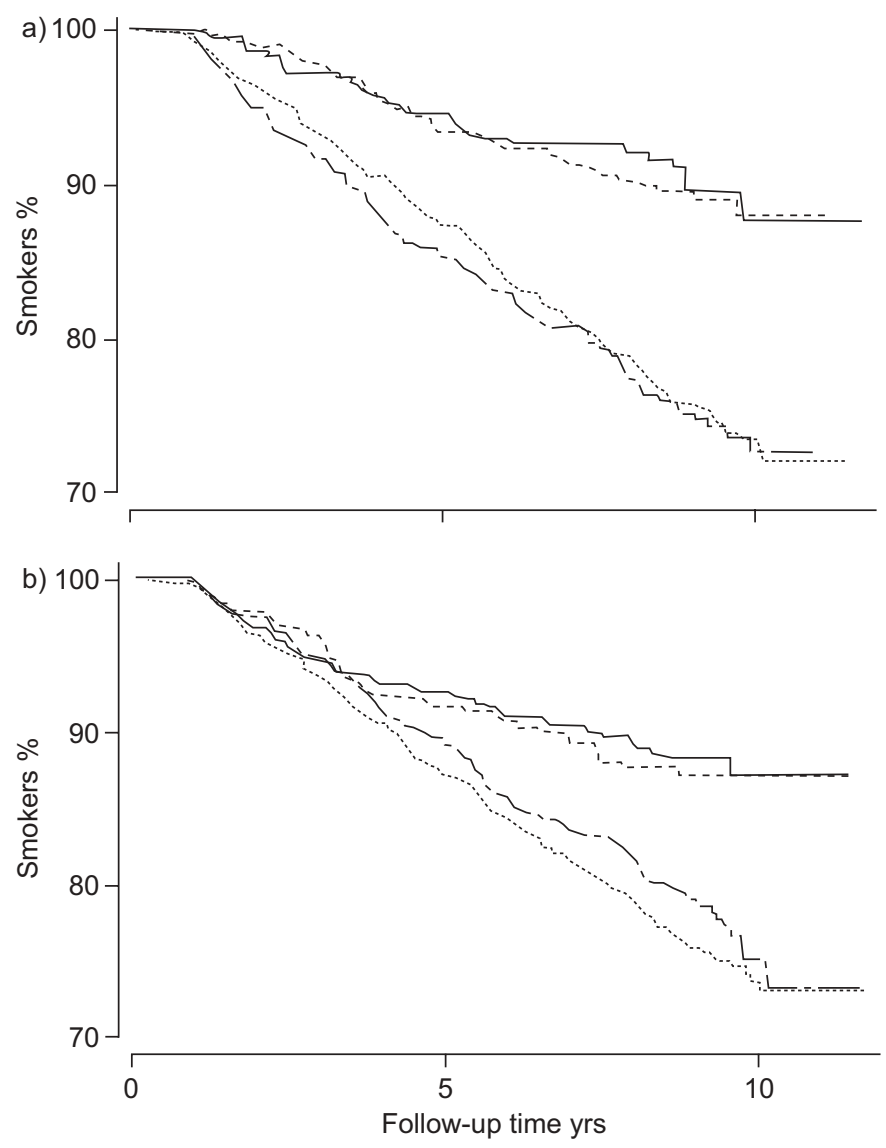

FIGURE 3. Proportion of smokers that continued smoking during the study period in relation to a) living with a smoker and b) workplace smoking. The subjects were divided into four groups: 1) no reported exposure in any of the surveys (- - - -); 2) reported exposure in the first but not the second survey (European Community Respiratory Health Survey (ECRHS) I only; - - -); 3) reported exposure in the second but not the first survey (ECRHS II only; - - -); and 4) reported exposure in both surveys $(-)$.

\section{DISCUSSION}

In this international cohort, a relatively modest decline in the prevalence of current smoking was found, while the exposure to passive smoking in nonsmokers decreased quite dramatically. The significant decline in the prevalence of current smoking is in accordance with what is seen in repeated national surveys [10-12]. The decline was not homogeneous between the centres, but no specific geographical pattern was found except quite a large increase in the prevalence of current smoking in Tartu in Estonia. This increase may be related to the large socio-economic changes in this society after the disintegration of the Soviet Union and the public marketing activities of the Western tobacco industry into these countries [23]. The large decrease in exposure to passive smoking in most of the centres is probably an effect of the increasing awareness of the negative effects of passive smoking among the general public in combination with legislative actions [7-9]. The present results are also in accordance with JARVIS et al. [13], who found a large decrease in exposure to passive smoking in English children during the 1990s. The magnitude of the decrease in passive smoking varied between different centres, although no distinct geographical pattern was found. Despite 


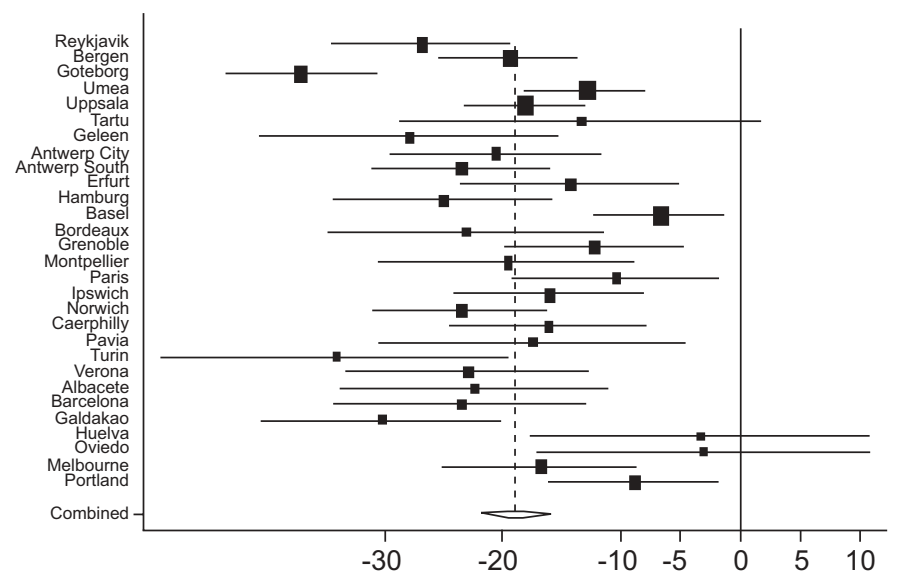

Net change in passive smoking $\%$ per 10 yrs

FIGURE 4. Net change in the prevalence of reported exposure to passive smoking in nonsmokers with $95 \%$ confidence interval $(\mathrm{Cl})$ in each centre. The area of each square is proportional to the reciprocal of the variance of the estimate for the centre. The diamond has the width of its $95 \% \mathrm{Cl}$. - - - -: combined random effects estimate.

the decrease, there still remain large differences in the prevalence of passive smoking in the different centres and, to some extent, this may be related to variations in legislation concerning smoke-free areas in Europe [9].

In the present study, the authors found that both active and passive smoking is increasingly becoming a socio-economic issue, with a lower quitting rate and a higher risk of becoming exposed to passive smoking in more deprived groups. The current data are in accordance with previous data showing that the social gradient in cigarette smoking has changed, with smoking becoming less common among persons with higher socio-economic status and relatively more frequent in less affluent social groups [24, 25]. A lower success rate in participants from lower socio-economic groups has also been found in smoking cessation studies [14, 15].

The present results underscore that apart from being a health hazard in itself, passive smoking also has a negative influence on smoking behaviour. Subjects living or working with smokers were less likely to have stopped smoking and the risk of starting to smoke was higher among subjects that were living with smokers. A higher quit rate in subjects with nonsmoking spouses has been reported in other studies [15, 16]. The effect of working with other smokers is less studied, but the current results support the findings of FICHTENBERG and GLANTZ [26] who reported that smoke-free workplaces reduce the prevalence of smoking. As in previous studies, the present authors found that smokers with a higher level of nicotine dependency or higher tobacco consumption were less likely to quit smoking $[15,17]$.

The decline in the prevalence of current smoking was lower in the youngest age group than among the older participants. The age difference was caused by a higher number of new starters among the younger participants. The decline in males was higher than in females. This trend has already been reported in many Western European countries [27]. The reason for this sex difference is unclear. It is well known that quitting smoking is

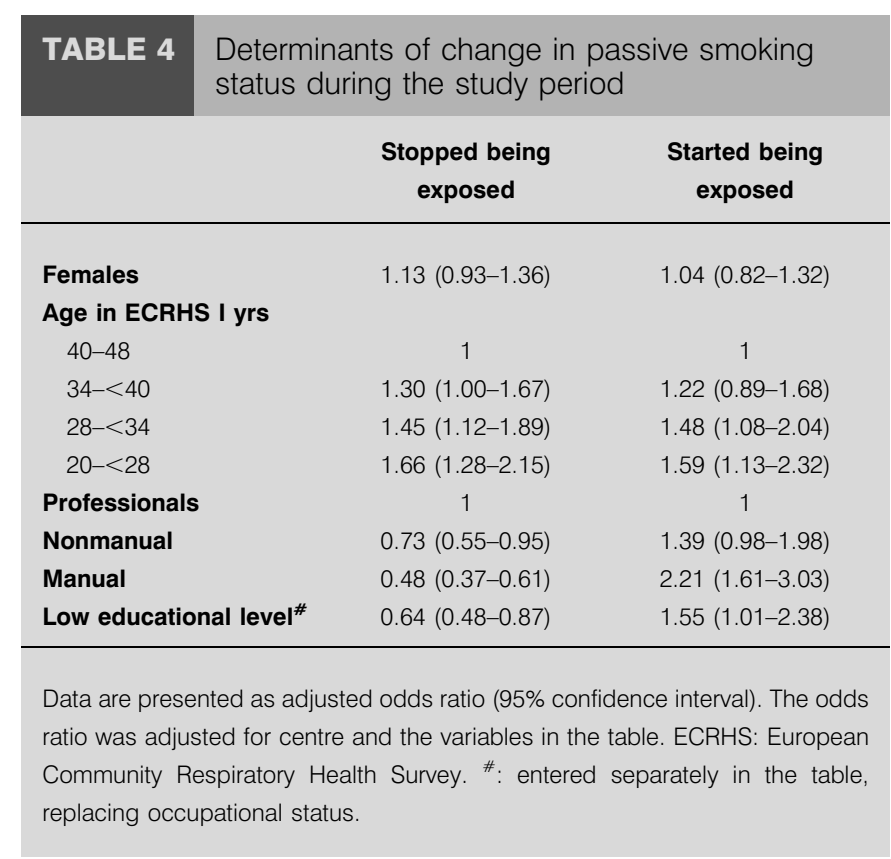

related to a moderate weight gain [20] and fear of increasing weight has been presented as an important obstacle for quitting [28]. The current results indicate that this obstacle may be present in females more than in males, since overweight females were significantly less likely to have quit smoking than females with a normal weight, whereas no such association was found in males.

A drawback of the present study is that there are no objective measurements of active or passive smoking. Results from previous studies indicate that self-reported data on these issues are fairly reliable $[29,30]$. The current authors also lack information regarding smoking cessation interventions, but as the participants were from general population samples, the numbers that have participated in such an intervention is probably small. In the present study, a subject was defined as an ex-smoker if they had not smoked within the last month. Increasing the required abstinence period to $1 \mathrm{yr}$ decreased the decline in smoking to $4.9 \%(4.0-5.8)$ per $10 \mathrm{yrs}$, but did not change any of the results of the other analyses.

Loss to follow-up is a problem in any longitudinal study and the present response rates are comparable to several recent population studies [31, 32]. Smokers were overrepresented among those not responding, which may result in an overestimation of the actual decline in current smoking. To some extent this was also true for passive smoking, although here the difference between participants and nonparticipants was smaller. It is also possible that loss of followup may have influenced the analyses of factors related to change in smoking habits. There was, however, no significance between country heterogeneity when analysing factors related to change in active and passive smoking, indicating that the effect of determinants for change in smoking status did not differ between countries with a higher or lower response rate. Re-analysing the data and only including centres with a response rate of $\geqslant 70 \%$ also gave almost identical results to the analyses with the whole data set (data not shown). 
In conclusion, the prevalence of active and passive smoking has decreased in this international cohort. The quitting rate was lower and the risk of exposure to passive smoking higher among subjects with lower socio-economic status and educational level. Exposure to other people's smoking at decreased quitting rates increased the risk of starting to smoke. This suggests that the current trends in active and passive smoking are widening social inequalities in health and that decreasing passive smoking may be an effective way of reducing active smoking in all social groups.

\section{ACKNOWLEDGEMENTS}

The members of the coordinating centre were as follows: P. Burney (project leader); S. Chinn (statistician); D. Jarvis (principle investigator); J. Knox (project coordinator); C. Luczynska (principle investigator); J. Potts (assistant statistician); S. Arinze (data manager).

The Steering Committee for the ECRHS II were as follows: U. Ackermann-Liebrich (University of Basel, Switzerland); N. Künzli (University of Basel, and University of Southern California, Los Angeles, USA); J.M. Antó and J. Sunyer (Institut Municipal d'Investigació Mèdica (IMIM-IMAS) Universitat Pompeu Fabra (UPF), Spain); P. Burney (project leader), S. Chinn, D. Jarvis, J. Knox and C. Luczynska (King's College London, UK); I. Cerveri (University of Pavia, Italy); R. de Marco (University of Verona, Italy); T. Gislason (Iceland University Hospital, Iceland); J. Heinrich and M. Wjst (GSFInstitute of Epidemiology, Germany); C. Janson (Uppsala University, Sweden); B. Leynaert and F. Neukirch (Institut National de la Santé et de la Recherche Médicale (INSERM), France); J. Schouten (University of Groningen, The Netherlands); C. Svanes (University of Bergen, Norway); P. Vermeire (University of Antwerp, Belgium).

The principal investigators and senior scientific team were as follows. Belgium: P. Vermeire, J. Weyler, M. Van Sprundel and V. Nelen (South Antwerp and Antwerp City). Estonia: R. Jogi and A. Soon (Tartu). France: F. Neukirch, B. Leynaert, R. Liard and M. Zureik (Paris); I. Pin and J. Ferran-Quentin (Grenoble). Germany: J. Heinrich, M. Wjst, C. Frye and I. Meyer (Erfurt). Iceland: T. Gislason, E. Bjornsson, D. Gislason, T. Blondal and K.B. Jorundsdottir (Reykjavik). Italy: M. Bugiani, P. Piccioni, E. Caria, A. Carosso, E. Migliore and G. Castiglioni (Turin); R. de Marco, G. Verlato, E. Zanolin, S. Accordini, A. Poli, V. Lo Cascio and M. Ferrari (Verona); A. Marinoni, S. Villani, M. Ponzio, F. Frigerio, M. Comelli, M. Grassi, I. Cerveri and A. Corsico (Pavia). The Netherlands: J. Schouten and M. Kerkhof (Groningen \& Geleen). Norway: A. Gulsvik, E. Omenaas, C. Svanes and B. Laerum (Bergen). Spain: J.M. Antó, J. Sunyer, M. Kogevinas, J.P. Zock, X. Basagana, A. Jaen, F. Burgos (Barcelona); J. Maldonado, A. Pereira and J.L. Sanchez (Huelva); J. Martinez-Moratalla Rovira and E. Almar (Albacete); N. Muniozguren and I. Urritia (Galdakao); F. Payo (Oviedo). Sweden: C. Janson, G. Boman, D. Norback and M. Gunnbjornsdottir (Uppsala); K. Toren, L. Lillienberg, A.C. Olin, B. Balder, A. Pfeifer-Nilsson and R. Sundberg (Goteborg); E. Norrman, M. Soderberg, K. Franklin, B. Lundback, B. Forsberg and L. Nystrom (Umea). Switzerland: N. Künzli, B. Dibbert, M. Hazenkamp, M. Brutsche and U. Ackermann-Liebrich (Basel). UK: D. Jarvis and B. Harrison (Norwich); D. Jarvis, R. Hall and D. Seaton (Ipswich).
The following took part at their own expense: A. Taytard and C. Raherison (Bordeaux, France); J. Bousquet and P. Demoly (Montpellier, France); K. Richter (Hamburg, Germany); M. Osborne, S. Buist, W. Vollmer and L. Johnson (Portland, OR, USA).

The coordination of the ECRHS II was supported by the European Commission as part of their Quality of Life programme.

The following bodies funded the local studies in the ECRHS II which are included in the present study. Belgium: Fund for Scientific Research-Flanders Belgium (grant code: G.0402.00); University of Antwerp, Flemish Health Ministry. Estonia: Estonian Science Foundation. France: Programme Hospitalier de Recherche Clinique-DRC de Grenoble 2000 no. 2610, Ministry of Health; Direction de la Recherche Clinique; $\mathrm{CHU}$ de Grenoble; Ministere de l'Emploi et de la Solidarite; Direction Generale de la Sante; Aventis; Direction Régionale des Affaires Sanitaires et Sociales Languedoc-Roussillon; Ministere de l'Emploi et de la Solidarite; Direction Generale de la Sante, UCB-Pharma; Glaxo France; Institut Pneumologique d'Aquitaine; Comite des Maladies Respiratoires de l'Isere. Germany: GSF-National Reasearch Centre for Environment \& Health; Deutsche Forschungsgemeinschaft (grant code MA 711/ 4-1 and grant code FR 1526/1-1). Iceland: Icelandic Research Council; Icelandic University Hospital Fund. Italy: ASL 4 Regione Piemonte; AO CTO/ICORMA Regione Piemonte; Ministero dell'Università e della Ricerca Scientifica; Glaxo Wellcome spa (Verona); Glaxo-SmithKline Italy; Italian Ministry of University and Scientific and Technological Research (MURST); Local University Funding for research 1998 \& 1999 (Pavia); University of Verona; Italian Ministry of University and Scientific and Technological Research (MURST). Norway: Norwegian Research Council; Norwegian Asthma \& Allergy Association (NAAF); Glaxo Wellcome AS; Norway Research Fund. Spain: Fondo de Investigaciones Santarias (grant code: 97/0035-01, 99/003401, 97/0035-01 and 99/0034-02); SEPAR; Public Health Service (grant code: R01 HL62633-01); CIRIT (grant code: 1999SGR 00241); Hospital Universitario de Albacete, Consejeria de Sanidad; Basque Health Dept. Sweden: Swedish Heart Lung Foundation; Swedish Foundation for Health Care Sciences \& Allergy Research; Swedish Asthma \& Allergy Foundation; Swedish Cancer \& Allergy Foundation; Swedish Heart Lung Foundation. Switzerland: Swiss National Science Foundation; Swiss Federal Office for Education \& Science; Swiss National Accident Insurance Fund (SUVA). UK: National Asthma Campaign. USA: American Lung Association of Oregon; Northwest Health Foundation; Collins Foundation; Merck Pharmaceutical.

Financial support for the ECRHS I and for centres in the ECRHS II was received from the following: Belgian Science Policy Office; National Fund for Scientific Research; Ministère de la Santé; Glaxo France; Insitut Pneumologique d'Aquitaine; Contrat de Plan Etat-Région Languedoc-Rousillon; CNMATS; CNMRT (90MR/10, 91AF/6); Ministre delegué de la santé; RNSP (France); GSF and the Bundesminister für Forschung und Technologie (Germany); Ministero dell'Università e della Ricerca Scientifica e Tecnologica; CNR; Regione Veneto grant RSF n. 381/05.93 (Italy); Norwegian Research Council project 
no. 101422/310; Dutch Ministry of Wellbeing; Public Health and Culture (The Netherlands); Ministero Sanidad y Consumo FIS (grants \#91/0016060/00E-05E and \#93/0393); grants from Hospital General de Albacete; Hospital General Juan Ramón Jiménenz; Consejeria de Sanidad Principado de Asturias (Spain); the Swedish Medical Research Council; the Swedish Heart Lung Foundation; the Swedish Association against Asthma and Allergy; Swiss National Science Foundation grant 4026-28099; National Asthma Campaign; British Lung Foundation; Department of Health (South Thames Regional Health Authority, UK); United States Department of Health, Education and Welfare Public Health Service (grant \#2 S07 RR05521-28).

\section{REFERENCES}

1 Slama K. Current challenges in tobacco control. Int J Tuberc Lung Dis 2004; 8: 1160-1172.

2 Dunn A, Zeine L, eds. Health effects of exposure to environmental tobacco smoke. Sacramento, CA, USA, California Environmental Protection Agency, 1997.

3 Cook DG, Strachan DP. Health effects of passive smoking10: Summary of effects of parental smoking on the respiratory health of children and implications for research. Thorax 1999; 54: 357-366.

4 Jamrozik K. Estimate of deaths attributable to passive smoking among UK adults: database analysis. BMJ 2005; 330: 812-815.

5 Cerveri I, Accordini S, Verlato G, et al. Variations in the prevalence across countries of chronic bronchitis and smoking habits in young adults. Eur Respir J 2001; 18: 85-92.

6 Janson C, Chinn S, Jarvis D, Zock JP, Toren K, Burney P. Effect of passive smoking on respiratory symptoms, bronchial responsiveness, lung function, and total serum $\mathrm{IgE}$ in the European Community Respiratory Health Survey: a cross-sectional study. Lancet 2001; 358: 2103-2109.

7 McNicholas WT. Controlling passive smoking through legislation in Ireland: an attack on civil liberty or good public health policy? Eur Respir J 2004; 24: 337-338.

8 Twombly R. Where there's no smoke: popular smoke-free laws curbing active, passive smoking. I Natl Cancer Inst 2004; 96: 1058-1060.

9 WHO Regional Office for Europe. Tobacco control database 2003. http://www.data.euro.who.int/?TabID=2402. Date last accessed: July 2005. Date last updated: June 2005.

10 Centers for Disease Control and Prevention (CDC). Cigarette smoking among adults-United States, 2002. MMWR Morb Mortal Wkly Rep 2004; 53: 427-431.

11 Fagerstrom KO, Schildt EB. Should the European Union lift the ban on snus? Evidence from the Swedish experience. Addiction 2003; 98: 1191-1195.

12 Gallus S, Colombo P, Scarpino V, Zuccaro P, Apolone G, La Vecchia C. Smoking in Italy, 2002. Tumori 2002; 88: 453-456.

13 Jarvis MJ, Goddard E, Higgins V, Feyerabend C, Bryant A, Cook DG. Children's exposure to passive smoking in England since the 1980s: cotinine evidence from population surveys. BMJ 2000; 321: 343-345.

14 Pisinger C, Vestbo J, Borch-Johnsen K, Jorgensen $T$. Smoking cessation intervention in a large randomised population-based study. The Inter99 study. Prev Med 2005; 40: 285-292.

15 Hymowitz N, Cummings KM, Hyland A, Lynn WR, Pechacek TF, Hartwell TD. Predictors of smoking cessation in a cohort of adult smokers followed for five years. Tob Control 1997; 6: Suppl. 2, S57-S62.

16 Chandola T, Head J, Bartley M. Socio-demographic predictors of quitting smoking: how important are household factors? Addiction 2004; 99: 770-777.

17 Godtfredsen NS, Prescott E, Osler M, Vestbo J. Predictors of smoking reduction and cessation in a cohort of Danish moderate and heavy smokers. Prev Med 2001; 33: 46-52.

18 The European Community Respiratory Health Survey II. Eur Respir J 2002; 20: 1071-1079.

19 Burney PG, Luczynska C, Chinn S, Jarvis D. The European Community Respiratory Health Survey. Eur Respir J 1994; 7: 954-960.

20 Chinn S, Jarvis D, Melotti R, et al. Smoking cessation: maximum benefit for lung function requires control of weight gain. Lancet 2005; 365: 1629-1635.

21 Liberatos P, Link BG, Kelsey JL. The measurement of social class in epidemiology. Epidemiol Rev 1988; 10: 87-121.

22 De Marco R, Accordini S, Cerveri I, et al. An international survey of chronic obstructive pulmonary disease in young adults according to GOLD stages. Thorax 2004; 59: 120-125.

23 Prokhorov A. Cigarette Smoking and Priorities for Tobacco Control in the New Independent States. In: Bobadilla JL, Christine A, Costello CA, Faith Mitchell F, eds. Premature Death in the New Independent States. National Academy of Sciences. Washington D.C., National Academy Press, 1997; pp. 275-286.

24 Jefferis BJ, Power C, Graham H, Manor O. Changing social gradients in cigarette smoking and cessation over two decades of adult follow-up in a British birth cohort. J Public Health (Oxf) 2004; 26: 13-18.

25 Faggiano F, Versino E, Lemma P. Decennial trends of social differentials in smoking habits in Italy. Cancer Causes Control 2001; 12: 665-671.

26 Fichtenberg CM, Glantz SA. Effect of smoke-free workplaces on smoking behaviour: systematic review. BMJ 2002; 325: 188.

27 Graham H. Smoking prevalence among women in the European community 1950-1990. Soc Sci Med 1996; 43: 243-254.

28 Filozof C, Fernandez Pinilla MC, Fernandez-Cruz A. Smoking cessation and weight gain. Obes Rev 2004; 5: 95-103.

29 Morabia A, Bernstein MS, Curtin F, Berode M. Validation of self-reported smoking status by simultaneous measurement of carbon monoxide and salivary thiocyanate. Prev Med 2001; 32: 82-88.

30 Olivieri M, Poli A, Zuccaro P, et al. Tobacco smoke exposure and serum cotinine in a random sample of adults living in Verona, Italy. Arch Environ Health 2002; 57: 355-359.

31 Guerra S, Wright AL, Morgan WJ, Sherrill DL, Holberg CJ, Martinez FD. Persistence of asthma symptoms during adolescence. Am J Respir Crit Care Med 2004; 170: 78-85.

32 James AL, Palmer LJ, Kicic E, et al. Decline in lung function in the Busselton Health Survey. Am J Respir Crit Care Med 2005; 171: 109-114. 